\title{
Study of selected thermoplastics using dynamic mechanical analysis
}

\author{
Marcel Kohutiar ${ }^{*}, 1$, Mariana Pajtášová $^{1}$, Róbert Janík ${ }^{1}$, Iveta Papučová $^{1}$, Jana Pagáčová $^{1}$, \\ Beáta Pecušová ${ }^{1}$, Ivan Labaj ${ }^{1}$ \\ Department of Materials Technologies and Environment, Faculty of Industrial Technologies in \\ Puchov, Alexander Dubcek University of Trencin, I. Krasku 491/30, 02001 Puchov, Slovak \\ Republic
}

\begin{abstract}
The aim of given paper is to study selected polymers using dynamic mechanical analysis method (DMA). DMA is one of the most useful techniques for the study of the viscoelastic behaviour of thermoplastic polymers. In relation to DMA, an oscillatory stress and strain is applied to the material at specific frequencies and temperatures and based on this mentioned fact hereinbefore, the resulting changes after the loading in the material are measured. This technique allows detecting the melting temperature and the glass transition temperature of the thermoplastic materials. Furthermore, some spectroscopy techniques, such as energy dispersive Xray spectroscopy (EDX) and infrared spectroscopy (IR), were also used for the investigation of the thermoplastics. The thermoplastics used for examination, namely polyethylene, polystyrene, polypropylene and polyethylene terephthalate, were gained from the waste of the packaging.
\end{abstract}

Keywords: Dynamic mechanical analysis, infrared spectroscopy, dispersive X-ray spectroscopy, thermoplastics, packaging

\section{Introduction}

Dynamic mechanical analysis (DMA) is a method commonly used to measure the viscoelastic behaviour of plastic materials [1]. Plastics are never purely liquid or purely solid, because they exhibit both viscous and elastic characteristics when undergoing deformation. Oscillatory stress and strain is applied to the material at appropriate frequencies and temperatures [2]. Based on this mentioned fact, the resulting changes after the loading in the material are measured. The use of DMA technique along with differential scanning calorimetry (DSC) allows detecting the melting temperature and the glass transition temperature of the thermoplastic materials [3].

Infrared spectroscopy is widely used for characterization of various materials, such as plastics, ceramics or chemicals. Infrared spectrum helps us to identify or characterize an unknown material, and also analyze contaminants or chemical differences in observed material [4]. Infrared spectroscopy can be also used for analyzing additives in plastic compounds. Along with the energy dispersive X-ray spectroscopy (EDX), which provides

\footnotetext{
* Corresponding author: marcel.kohutiar@gmail.com

Reviewers: František Nový, Eva Tillová
} 
elemental and chemical analysis of the sample, this method has become more important for the identification of potential harmful substances occurring in packaging [5,6]. Materials for packaging can not contain toxic substances and have to be tough and flexible enough to protect the food from damage and to keep its freshness [7]. Nowadays, the most commonly used thermoplastics in the manufacture of food packaging are polyethylene, polystyrene, polypropylene and polyethylene terephthalate $[8,9]$.

\section{Materials and methods}

For the experiment, two types of low density polyethylene (LDPE), polypropylene (PP) and polyethylene terephthalate (PET) were selected as the examined materials. The thermoplastics used for examination were gained from the waste of the packaging.

Dynamic mechanical analysis was performed by the Q800 DMA from TA Instruments. The dimensions of each sample for DMA were $45 \times 10 \mathrm{~mm}$. The testing temperature was from $-70{ }^{\circ} \mathrm{C}$ to $100{ }^{\circ} \mathrm{C}$ for LDPE, from $-70{ }^{\circ} \mathrm{C}$ to $140{ }^{\circ} \mathrm{C}$ for PP, from $-70{ }^{\circ} \mathrm{C}$ to $160{ }^{\circ} \mathrm{C}$ for PET at a heating rate of $3^{\circ} \mathrm{C}$ per minute and frequency was $10 \mathrm{~Hz}$.

The DSC measurements described in this paper were performed using Mettler Toledo, TGA/DSC 2 instrument. The weight of the samples was about from 10 to $20 \mathrm{mg}$ and they were heated from $0{ }^{\circ} \mathrm{C}$ to $350{ }^{\circ} \mathrm{C}$ at a heating rate of $10{ }^{\circ} \mathrm{C} \mathrm{min}^{-1}$.

In Fourier transform infrared spectroscopy (FTIR), the spectra were measured by ATR technique using a Nicolet iS50 FT-IR spectrometer with a resolution of $4 \mathrm{~cm}^{-1}$ in the range of $4000-400 \mathrm{~cm}^{-1}$. The elemental and chemical analysis of the samples, were carried out using energy-dispersive EDX-7000 X-ray fluorescence spectrometer. All measurements were carried out at the CEDITEK (Center for quality testing and diagnostics of materials) workplace at Faculty of Industrial Technologies in Puchov.

\section{Results and discussions}

\subsection{Dynamic mechanical analysis (DMA)}

Fig. 1. shows the scan temperature data at frequency of $10 \mathrm{~Hz}$ for transparent and red LDPE. There is a decrease in storage modulus at approximately $-46{ }^{\circ} \mathrm{C}$ for red and at approximately $-30{ }^{\circ} \mathrm{C}$ for transparent sample which can be attributed to the $\beta$-relaxation or glass transition temperature $\left(\mathrm{T}_{\mathrm{g}}\right)$. The loss modulus of red LDPE shows one well-defined transition and two small transitions while at transparent LDPE, all three transitions are well evident. The first peak of red sample at $-29{ }^{\circ} \mathrm{C}$ may be attributed to the $\beta$-relaxation. The second and the third small peaks at approximately $25{ }^{\circ} \mathrm{C}$ and $49{ }^{\circ} \mathrm{C}$ may correspond with the $\alpha$-relaxation, but it can also correspond with the melting of the small crystallites.

The possible $\beta$-relaxation of transparent sample occurs at approximately $0{ }^{\circ} \mathrm{C}$. The second and the third peaks associated with the $\alpha$-relaxation and the melting of small crystallites are at approximately $28{ }^{\circ} \mathrm{C}$ and at approximately $55{ }^{\circ} \mathrm{C}$. There is increase in tan $\delta$ for both samples with peak of red LDPE at approximately $56{ }^{\circ} \mathrm{C}$ associated with $\alpha$ relaxation. 


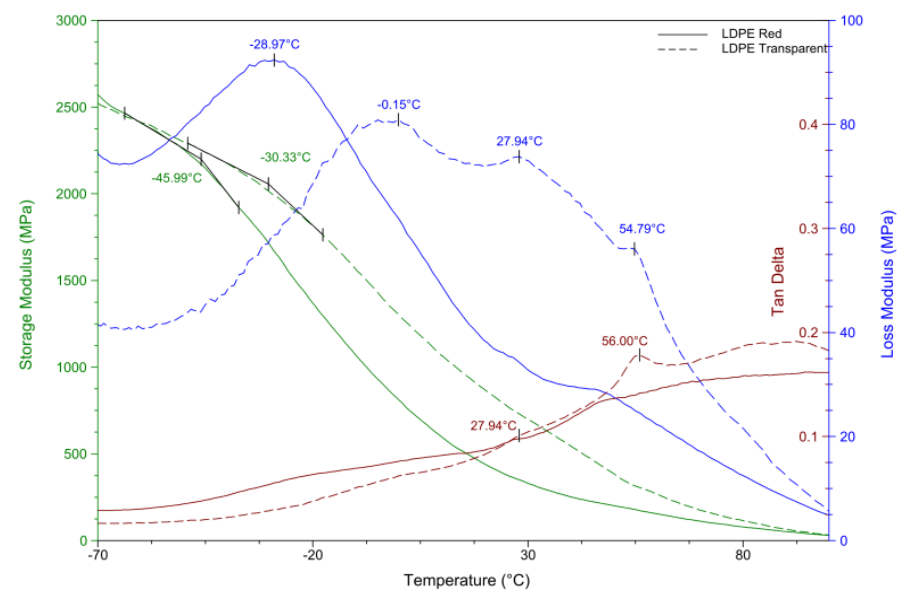

Fig. 1. Dynamic mechanical analysis of LDPE samples

The scan temperature data at frequency of $10 \mathrm{~Hz}$ for transparent and yellow PP are shown in Fig. 2. There is a decrease in storage modulus at approximately $-18{ }^{\circ} \mathrm{C}$ for yellow and at approximately $-7{ }^{\circ} \mathrm{C}$ for transparent PP which corresponds with glass transition temperature of materials. The loss modulus shows two temperature peaks for both samples at approximately $-41{ }^{\circ} \mathrm{C}$ and $4{ }^{\circ} \mathrm{C}$ for transparent sample and at approximately $-42{ }^{\circ} \mathrm{C}$ and $-5{ }^{\circ} \mathrm{C}$ for yellow sample. These peaks are associated with the $\alpha$ - and $\beta$ transitions of polypropylene. The $\tan \delta$ also shown two peaks associated with these transitions. The peaks of transparent PP are at approximately $-42{ }^{\circ} \mathrm{C}$ and $10{ }^{\circ} \mathrm{C}$ for transparent sample and at approximately $-43{ }^{\circ} \mathrm{C}$ and $2{ }^{\circ} \mathrm{C}$ for yellow sample.

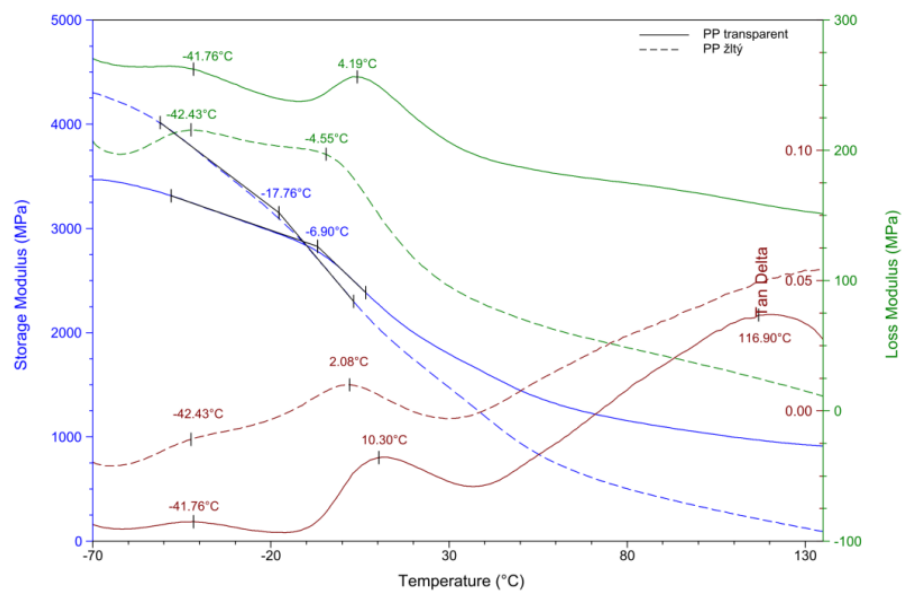

Fig. 2. Dynamic mechanical analysis of PP samples

The scan temperature data of pink and green PET at frequency of $10 \mathrm{~Hz}$ are shown in Fig. 3. The storage modulus of both samples shows well-defined peaks which correspond with glass transition temperature of PET. The peak for pink sample is determined at approximately $73{ }^{\circ} \mathrm{C}$, while for green sample, it is at approximately $94{ }^{\circ} \mathrm{C}$. The glass transition temperature can be also determined from loss modulus and from tan $\delta$. From loss modulus, the $\mathrm{T}_{\mathrm{g}}$ for pink sample is at approximately $93{ }^{\circ} \mathrm{C}$ and for green sample, it is approximately $103{ }^{\circ} \mathrm{C}$, whereas from tan $\delta$, the $\mathrm{T}_{\mathrm{g}}$ for pink sample is at approximately $105^{\circ} \mathrm{C}$ and for green sample, it is at approximately $117^{\circ} \mathrm{C}$. 


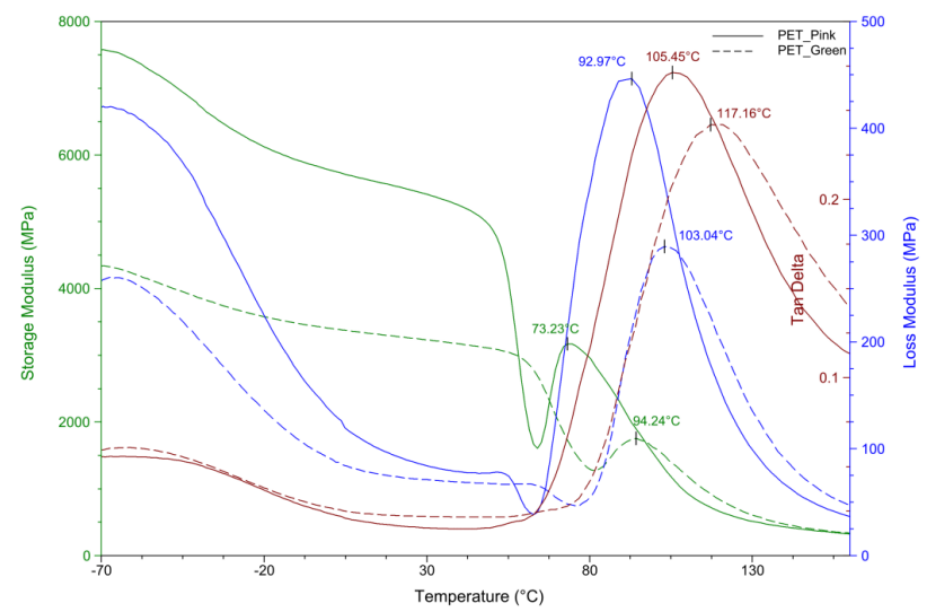

Fig. 3. Dynamic mechanical analysis of PET samples

\subsection{Differential scanning calorimetry (DSC)}

Differential scanning calorimetry was used for detecting the glass transition temperature and melting point of investigated materials. Fig. 4. presents DSC measurements of red and transparent LDPE samples. As can be seen from the graph, the melting peak of red LDPE is less sharp and wider in comparison with transparent LDPE. The melting point of red sample is at approximately $116^{\circ} \mathrm{C}$. The second peak is at approximately $164{ }^{\circ} \mathrm{C}$. This peak is most likely result of the residual reactants from LDPE synthesis or contamination before analysis. Furthermore, the melting point of transparent LDPE is at approximately $121^{\circ} \mathrm{C}$.

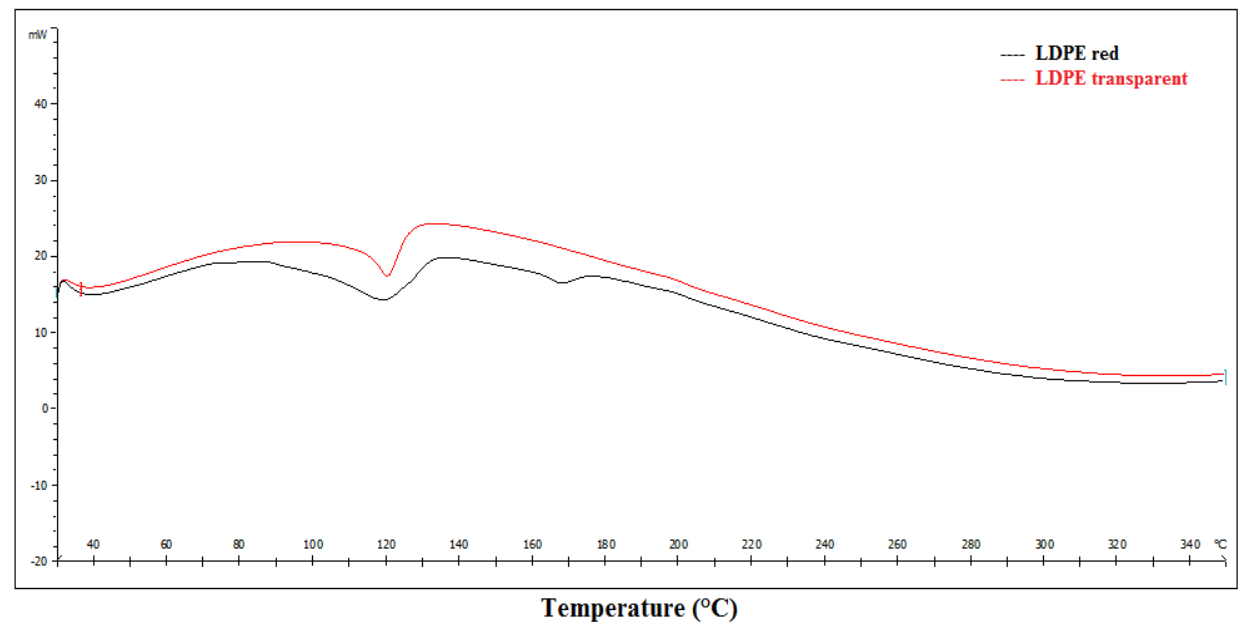

Fig. 4. DSC measurement of LDPE samples

DSC measurements of yellow and transparent PP samples are presented in Fig. 5. The melting peak of yellow PP is sharper and narrower in comparison with the transparent one. The melting point of yellow sample is at approximately $173^{\circ} \mathrm{C}$ while the melting point of transparent sample is at approximately $171^{\circ} \mathrm{C}$. 


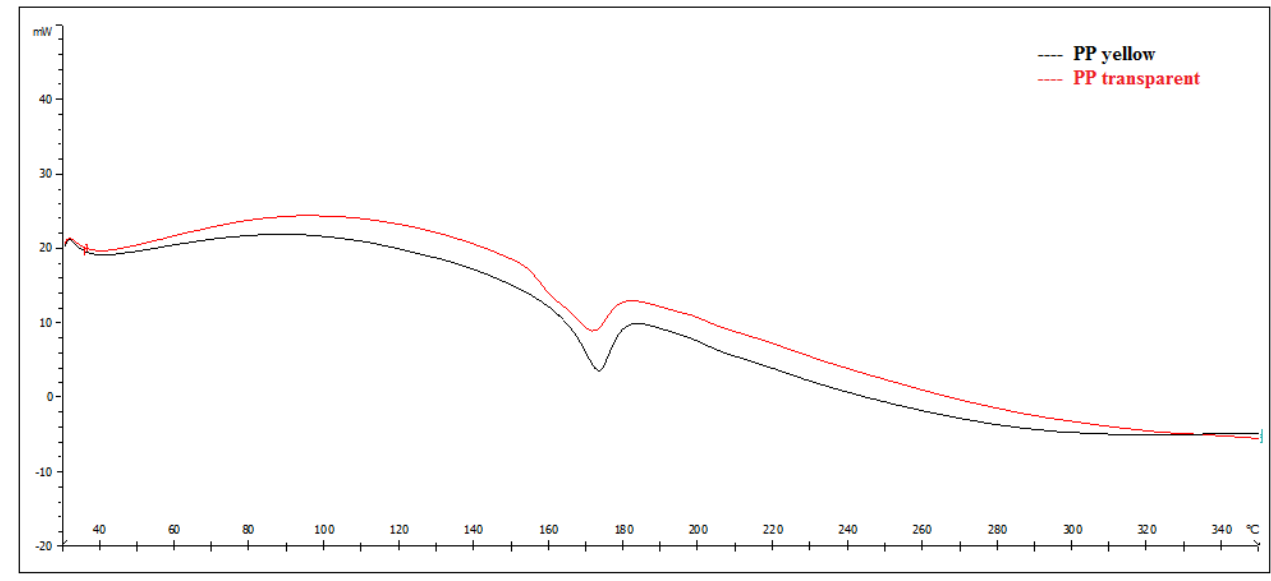

Temperature $\left({ }^{\circ} \mathbf{C}\right)$

Fig. 5. DSC measurement of PP samples

Fig. 6. shows DSC measurements of pink and green PET samples. In contrast to the samples described above, the glass transition temperature is shown in the graph. The glass transition peak of pink and green sample is at approximately $104{ }^{\circ} \mathrm{C}$ and at approximately $98{ }^{\circ} \mathrm{C}$, respectively. The melting point of pink sample is at approximately $151^{\circ} \mathrm{C}$ while the melting point of green sample is at approximately $152^{\circ} \mathrm{C}$.

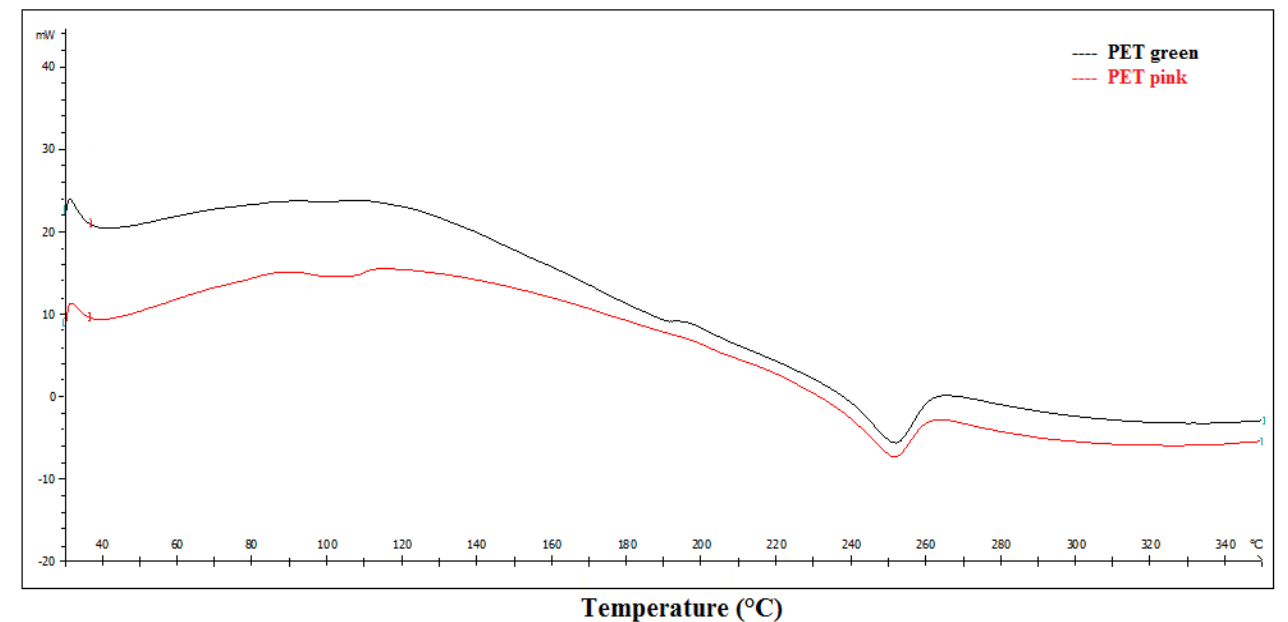

Fig. 6. DSC measurement of PET samples

\subsection{Fourier transform infrared spectroscopy (FTIR)}

The spectra of transparent and red LDPE samples obtained in absorbance using ATR technique is shown in Fig. 7. As can be seen from data, LDPE samples are very similar, because there are only differences in peak intensity. Characteristic peaks at around 3000 $2800 \mathrm{~cm}^{-1}$ correspond with methylene group symmetric stretching $v_{\mathrm{s}}\left(\mathrm{CH}_{2}\right)$ and asymmetric stretching $v_{\mathrm{as}}\left(\mathrm{CH}_{2}\right)$. Peak at around $1500-1400 \mathrm{~cm}^{-1}$ can be associated with $\mathrm{CH}_{2}$ due to sccisoring. The rocking of methylene group is presented by peaks between 750 and $700 \mathrm{~cm}^{-1}$. 

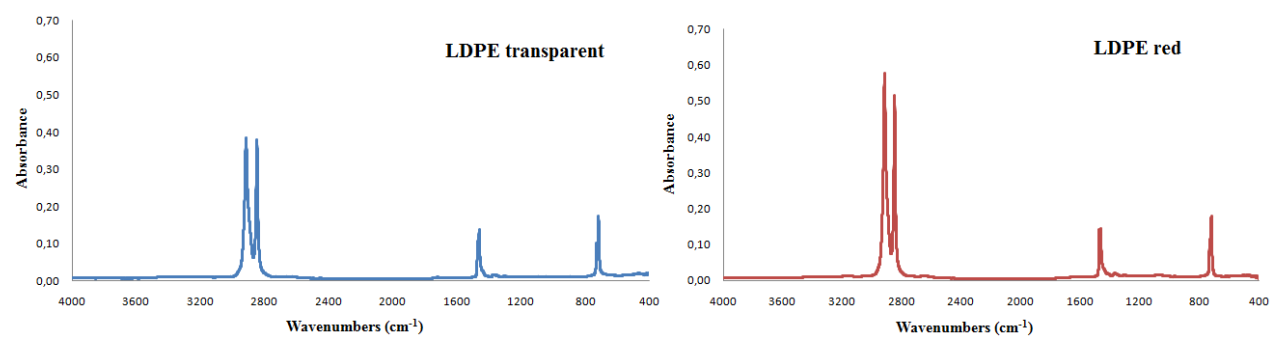

Fig. 7. Measured spectra of LDPE samples

Fig. 8. presents measured spectra of transparent and yellow PP samples obtained in absorbance using ATR technique. From the FTIR spectra scan be seen, that there is similarity between two samples. They are different in $800-400 \mathrm{~cm}^{-1}$ IR spectra region. At around $3000-2800 \mathrm{~cm}^{-1}$, polypropylene spectral areas present absorption bands which correspond with asymmetric and symmetric stretching vibration of methylene and methyl groups. Different peaks have been also observed in the $1500-1350 \mathrm{~cm}^{-1}$ spectral area, where absorption bands can be associated with scissoring vibration of the methylene group (at around $1470 \mathrm{~cm}^{-1}$ ) and to symmetric deformation of the methylene group (at around $\left.1380 \mathrm{~cm}^{-1}\right)$.
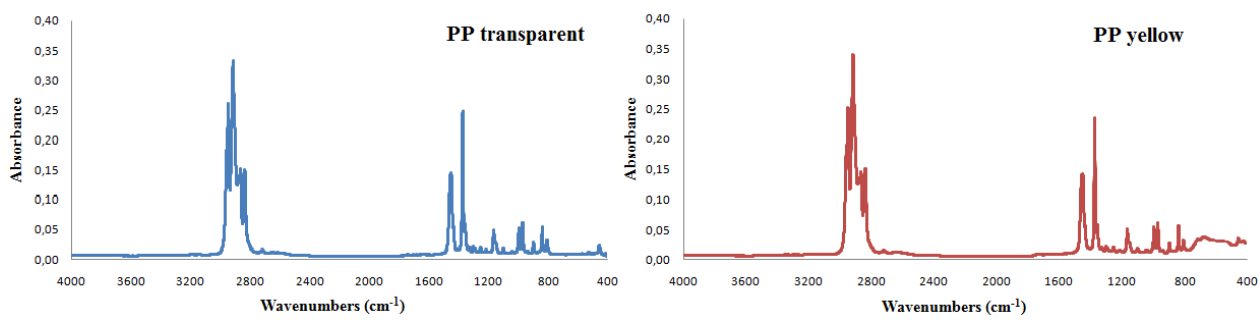

Fig. 8. Measured spectra of PP samples

Measured spectra of pink and green PET samples obtained in absorbance using ATR technique are presented in Fig. 8. There is no significant difference between the two PET samples compared with the FTIR spectra scan, because there are differences only in spectra intensity. The weak peak at around $2950 \mathrm{~cm}^{-1}$ represents C-H asymmetric stretching. Spectra of PET also confirm a carbonyl group along with aromatic ring appear as the second strongest peak at around $1720 \mathrm{~cm}^{-1}$. Two peaks at around $1410 \mathrm{~cm}^{-1}$ and $1340 \mathrm{~cm}^{-1}$ represent the deformation of $\mathrm{C}-\mathrm{H}$ alkane and peak at around $1510 \mathrm{~cm}^{-1}$ belongs to aromatic $\mathrm{C}-\mathrm{C}$ stretching. The asymmetric $\mathrm{C}-\mathrm{C}-\mathrm{O}$ stretching involving the carbon in aromatic ring appears at around $1230 \mathrm{~cm}^{-1}$ as a strong peak. The strongest peak at around $720 \mathrm{~cm}^{-1}$ is associated with aromatic C-H wagging. The peak at approximately $870 \mathrm{~cm}^{-1}$ corresponds with aromatic C-H bending. The O-C-C asymmetric stretching is at around $1105 \mathrm{~cm}^{-1}$. 

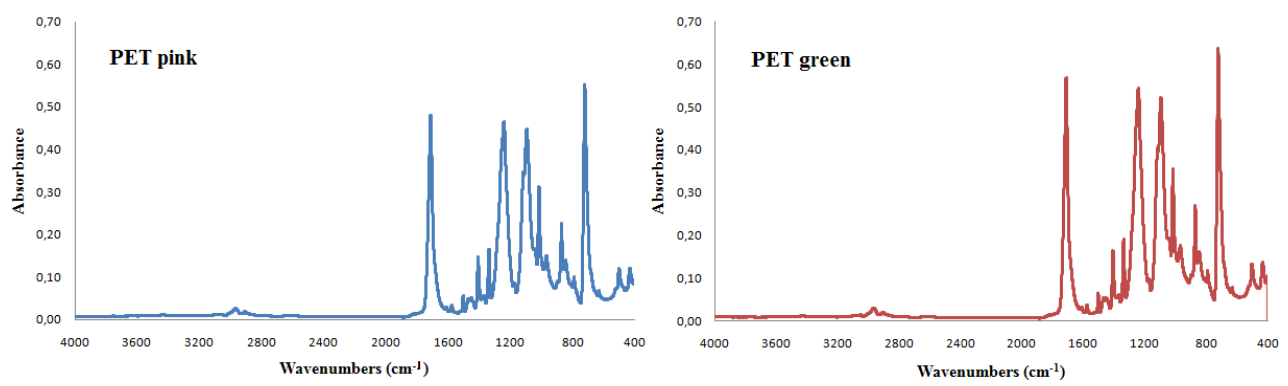

Fig. 9. Measured spectra of PET samples

\subsection{Energy-dispersive X-ray fluorescence spectroscopy (EDX)}

Thermoplastics used for food packaging contain low concentrations of heavy metals. Additives presented in quantity of products make heavy metals quantification very difficult. Antioxidants can contain $\mathrm{Ni}$, while thermal stabilizers can contain $\mathrm{Ni}, \mathrm{Pb}$ and $\mathrm{Sb}$. The polymerization process is often carried out with an antimony ( $\mathrm{Sb})$, germanium $(\mathrm{Ge})$, titanium (Ti), cobalt (Co), magnesium $(\mathrm{Mg})$ or zinc $(\mathrm{Zn})$ based catalyst [10].

EDX analysis of LDPE, PP and PET samples revealed percentage representation of individual elements in polymer matrix. As can be seen in Table 1., red sample contains increased amount of titanium and little amount of silicon and calcium, compared with transparent one. The presence of these elements in red sample can be due to used colorants or UV stabilizers.

Table 1. EDX analysis of LDPE samples

\begin{tabular}{|c|c|c|c|}
\hline \multicolumn{2}{|c|}{ LDPE red } & \multicolumn{2}{c|}{ LDPE transparent } \\
\hline Element & Content (\%) & Element & Contents (weight \%) \\
\hline $\mathrm{Ti}$ & 0.498 & $\mathrm{~S}$ & 0.008 \\
\hline $\mathrm{Si}$ & 0.093 & $\mathrm{P}$ & 0.007 \\
\hline $\mathrm{Ca}$ & 0.018 & $\mathrm{Fe}$ & 0.001 \\
\hline $\mathrm{S}$ & 0.004 & $\mathrm{~K}$ & 0.001 \\
\hline $\mathrm{K}$ & 0.003 & $\mathrm{Cr}$ & 0.001 \\
\hline $\mathrm{Fe}$ & 0.001 & $\mathrm{Cu}$ & 0.001 \\
\hline
\end{tabular}

According to Table 2, yellow PP sample also contain increased amount of titanium and calcium, compared with transparent LDPE and PP. As mentioned above, residue of titanium can be from polymerization process, where it was used in the form of catalyst.

The percentage representation of elements in PET samples is shown in Table 3. From the table, it can be clearly seen that both samples contain small amount of sulphur. Pink sample also contains increased amount of antimony which was most likely used in the form of catalyst during polycondensation of PET.

Table 2. EDX analysis of PP samples

\begin{tabular}{|c|c|c|c|}
\hline \multicolumn{2}{|c|}{ PP yellow } & \multicolumn{2}{c|}{ PP transparent } \\
\hline Element & Contents (weight \%) & Element & Contents (weight \%) \\
\hline $\mathrm{Ti}$ & 0.390 & $\mathrm{P}$ & 0.008 \\
\hline $\mathrm{Ca}$ & 0.127 & $\mathrm{~S}$ & 0.007 \\
\hline $\mathrm{P}$ & 0.018 & $\mathrm{~K}$ & 0.002 \\
\hline $\mathrm{S}$ & 0.013 & $\mathrm{Ca}$ & 0.002 \\
\hline $\mathrm{K}$ & 0.003 & $\mathrm{Fe}$ & 0.001 \\
\hline $\mathrm{Cr}$ & 0.002 & $\mathrm{Cr}$ & 0.001 \\
\hline
\end{tabular}


Table 3. EDX analysis of PET samples

\begin{tabular}{|c|c|c|c|}
\hline \multicolumn{2}{|c|}{ PET pink } & \multicolumn{2}{c|}{ PET green } \\
\hline Element & Contents (weight \%) & Element & Contents (weight \%) \\
\hline $\mathrm{Sb}$ & 0.017 & $\mathrm{~S}$ & 0.019 \\
\hline $\mathrm{S}$ & 0.016 & $\mathrm{Ca}$ & 0.004 \\
\hline $\mathrm{P}$ & 0.011 & $\mathrm{~K}$ & 0.002 \\
\hline $\mathrm{Ca}$ & 0.005 & $\mathrm{Co}$ & 0.001 \\
\hline $\mathrm{K}$ & 0.001 & $\mathrm{Cu}$ & 0.001 \\
\hline $\mathrm{Cu}$ & 0.001 & $\mathrm{Fe}$ & 0.001 \\
\hline
\end{tabular}

\section{Conclusions}

The measurements were carried out for six samples of thermoplastics, namely LDPE (red and transparent), PP (yellow and transparent) and PET (pink and green). Using DMA and DSC analysis, all the samples were measured and from the resulting graphs, the glass transition temperature and the melting point of each polymer was determined. There are several results of glass transition temperature, because it can be derived from the loss modulus, the storage modulus and the $\tan \delta$. It is because each of these results has its own physical essence.

Using the ATR-FTIR spectrometry, the spectra of the individual pairs of polymers were compared. Based on the results obtained in this work, it can be concluded that the ATR FTIR spectrometry is useful tool for examination of the chemical structure of thermoplastics.

Furthermore, the EDX analysis revealed the presence of some elements and heavy metals in tested polymers.

KEGA 007TnUAD-4/2017, VEGA grant No. 1/0649/17, VEGA grant No. 1/0589/17, project "Center for quality testing and diagnostics of materials", ITMS code 26210120046 relating to the Operational Program Research and Development, EF of Reg. Development.

\section{References}

1. K. P. Menard, Dynamic mechanical analysis: A practical introduction. (CRC Press, Boca Raton, 1999) ISBN 0849386888

2. J. Babíková, Využití metod DMA pro studium polymerních materiálů. Bachelor's thesis, Tomáš Bat’a University in Zlín, Faculty of Technology (2011)

3. I. Škrombachová, Dynamic mechanical properties of polymer blends. Bachelor's thesis. TnU AD, FPT (2011)

4. Da-Wen Sun, Infrared Spectroscopy for Food Quality Analysis and Control. (Elsevier, 2009) ISBN 978-0-12-374136-3 [online] Available at: <http://app.knovel. com/hotlink/toc/id:kpISFQAC0I/infrared-spectroscopy/infrared-spectroscopy>

5. K L. Yam, Wiley encyclopedia of packaging technology. (John Wiley \& Sons, $3^{\text {rd }}$ Edition, 2009) ISBN 978-0-470-08704-6 [online] Available at: $<$ http://app.knovel.com/hotlink/toc/id:kpWEPTE002/wiley-encyclopedia-packaging/ wiley encyclopedia-packaging $>$

6. G. L. Robertson, Foodpackaging : Principles and practice. (Taylor \& Francis, $3^{\text {rd }}$ Edition, 2013) ISBN 978-1-4398-6242-1 [online] Available at: 
$<$ http://app.knovel.com/hotlink/toc/id:kpFPPPE00I/food-packaging-principles/foodpackaging-principles $>$

7. S. Allahvaisi, Polypropylene : Polypropylene in the industry of food packaging. InTech (2012) ISBN 978-953-51-0636-4 [online] Available at: <https://www. intechopen.com/books/polypropylene>

8. M. Bělašková, Characterization of wrappaging films based on polyethylene and polypropylene. Bachelor's thesis, Brno University of Technology, Faculty of Chemistry (2015)

9. T. Liptáková, Polymérne konštrukčné materály. (Vydavatel'stvo Žilinskej univerzity, 2012) ISBN 978-80-554-0505-6

10. M. E. Conti, Heavy metals in food packaging. (University of Rome, Italy, 2009) 